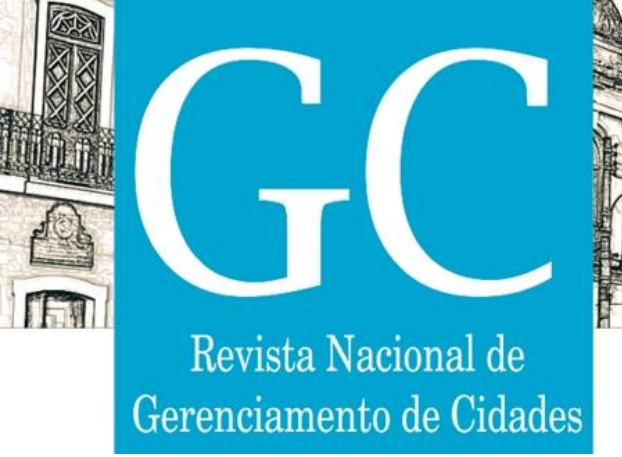

ISSN 2318-8472

v. 07, n. 52,2019

\title{
Projeto e avaliação de custos de um sistema compacto de wetlands construídos para habitação social no município de Bauru-SP
}

Design and cost assessment of a constructed wetlands compact system for affordable housing in Bauru-SP

Diseño e evaluación de costos de un sistema compacto de humedales construidos para viviendas sociales en Bauru-SP

Maria Fernanda Nóbrega dos Santos

Pesquisadora de Pós-Doutorado, UNESP, Brasil. mfnsantos@yahoo.com.br

Marta Enokibara Professora Doutora, UNESP, Brasil. marta.enokibara@unesp.br

Eduardo Luiz de Oliveira Professor Doutor, UNESP, Brasil. el.oliveira@unesp.br 

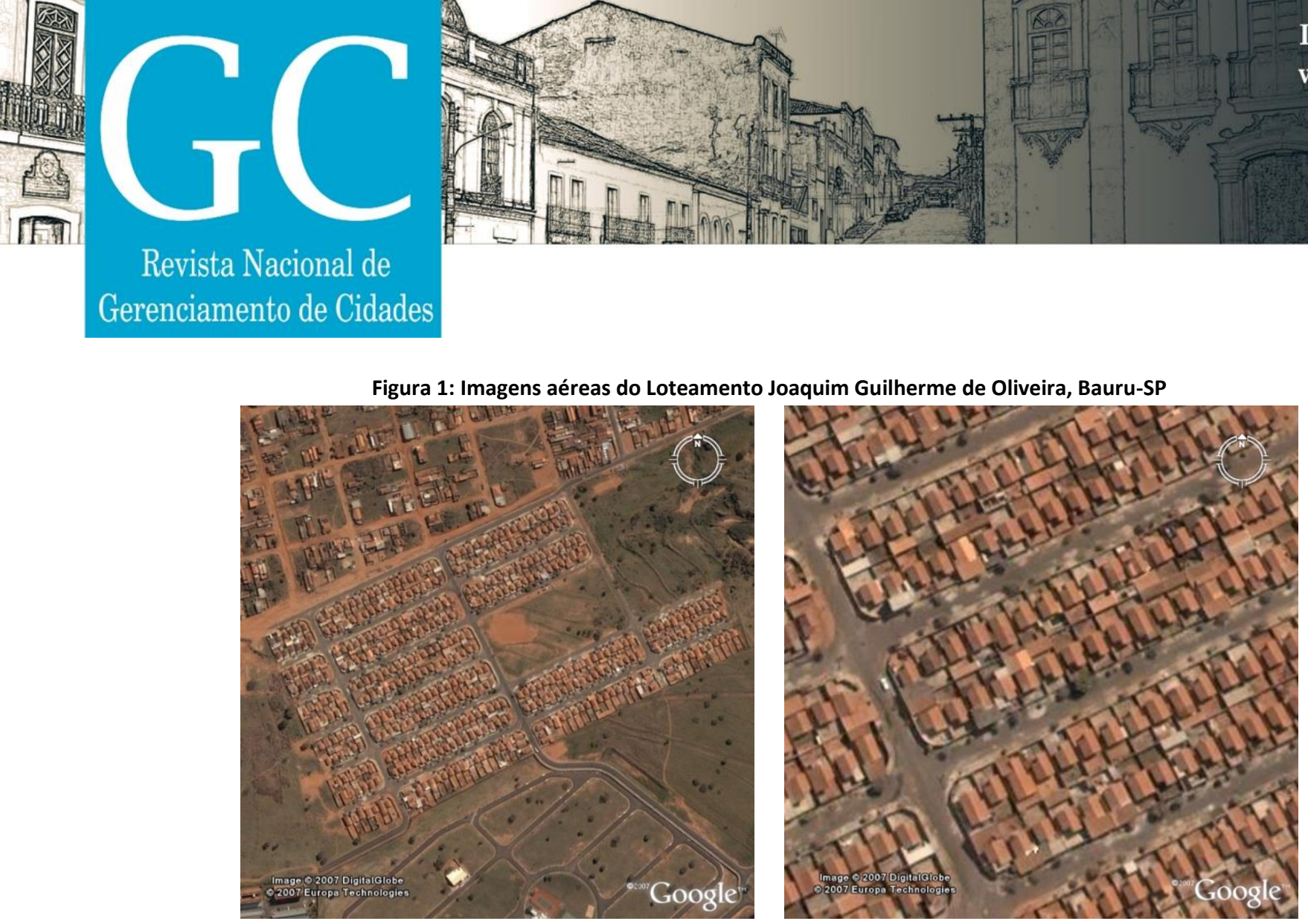

Fonte: Elaborado pelos autores, com base em Google Maps (2007).

Também é necessário avaliar o local com relação à topografia, ao tipo de solo da região e a existência de outros sistemas de tratamento. Em relação ao solo da cidade de Bauru, predomina o Latossolo Vermelho-Escuro fase Arenosa, com possíveis ocorrências de Solos Podzolizados de textura média (CAVASSAN et al., 1984). Já com relação à topografia, para tornar o projeto mais amplo e possível de ser implantado em diferentes situações, foram avaliados os tipos mais comuns de lotes: com inclinação para frente; com inclinação para o fundo; e os lotes planos.

Aualmente, estima-se que apenas $10 \%$ da população do município de Bauru possui o esgoto tratado, sendo que a Estação de Tratamento de Esgoto (ETE) prevista para entrar em funcionamento no ano de 2014 ainda não foi concluída, conforme informações do Departamento de Água e Esgoto de Bauru (DAE, 2019). A respeito do clima, de acordo com Figueiredo e Paz (2010, p. 5): “A classificação climática para Bauru é clima Úmido (B), Mesotérmico ( $\left.B^{\prime}\right)$, com moderada eficiência da umidade no verão (s) e marcha anual da temperatura (b) concentrada em cerca de seis meses no ano (outubro-março) [...]".

$\mathrm{Na}$ Tabela 1, apresenta-se um resumo das principais informações utilizadas para o dimensionamento do sistema de wetlands para o loteamento Joaquim Guilherme de Oliveira.

Tabela 1: Informações para dimensionamento dos wetlands construídos

\begin{tabular}{|c|c|c|}
\hline Informações para dimensionamento dos wetlands construídos & Valor & Unidade \\
\hline Número de habitantes da residência & 5 & hab \\
\hline $\begin{array}{l}\text { Água potável consumida por dia (considera-se um consumo médio } \\
\text { de } 200 \text { I por habitante para a cidade de Bauru) }\end{array}$ & 1000 & 1 \\
\hline $\begin{array}{l}\text { Quantidade de água lançada no esgoto sanitário por dia } \\
\text { (considera-se um valor de } 80 \% \text { do consumo diário de água potável) }\end{array}$ & 800 & 1 \\
\hline $\begin{array}{l}\text { Área de tratamento para o volume de esgoto (considera-se que } \\
\text { cada habitante necessita de uma área de tratamento de } 2 \mathrm{~m}^{2} \text { ) }\end{array}$ & 10 & $\mathrm{~m}^{2}$ \\
\hline
\end{tabular}

Fonte: Elaborado pelos autores, 2019. 


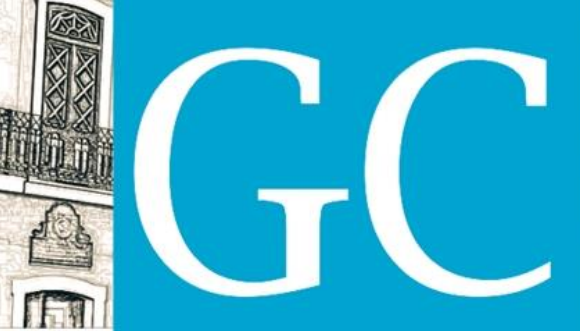

Revista Nacional de

Gerenciamento de Cidades

Antes dos efluentes iniciarem o tratamento no sistema de wetlands é necessária a présedimentação em uma fossa séptica, que funciona como um decantador primário. Para estabelecer o diâmetro necessário da fossa, foi empregada a metodologia apresentada pela Associação Brasileira de Normas Técnicas (ABNT NBR 7229:1993), que dispõe sobre o projeto, construção e operação de sistemas de tanques sépticos. O volume da fossa séptica para cada lote foi estimado em 2.085 litros, segundo a equação:

$$
V=1000+N(C T+K L f)
$$

Sendo:

$V=$ volume útil, em litros

$N=$ número de pessoas ou unidades de contribuição

$C=$ contribuição de despejos, em litro/pessoa $\mathrm{x}$ dia ou em litro/unidade $\mathrm{x}$ dia, ver Tabela $1 \mathrm{da}$ ABNT NBR 7229 (1993)

$T$ = período de detenção, em dias, ver Tabela 2 da ABNT NBR 7229 (1993)

$K=$ taxa de acumulação de lodo digerido em dias, equivalente ao tempo de acumulação de lodo fresco, ver Tabela 3 da ABNT NBR 7229 (1993)

$L f=$ contribuição de lodo fresco, em litro/pessoa $\mathrm{x}$ dia ou em litro/unidade $\mathrm{x}$ dia, ver Tabela 1 da ABNT NBR 7229 (1993)

Após a pré-sedimentação ocorrida na fossa séptica, é necessária a passagem dos efluentes pela caixa de entrada. A caixa de entrada se constitui de um reservatório de $100 \mathrm{~cm}$ de largura x $50 \mathrm{~cm}$ de comprimento $x 70 \mathrm{~cm}$ de profundidade, com a função de distribuir os efluentes nas duas células de tratamento. Além da caixa de entrada, o sistema necessita de uma caixa de saída, com as mesmas dimensões da caixa de entrada. Além disso, conforme a quantidade de efluentes que deverá percorrer o sistema, estabeleceu-se o diâmetro da tubulação: $100 \mathrm{~mm}$ de diâmetro em todas as etapas do sistema projetado.

A última etapa do trabalho é o estudo da viabilidade econômica do projeto, já que o aspecto econômico é um grande incentivador para a dissipação (ou não) de algumas práticas. De acordo com Campbell e Ogden (1999), o gasto com a construção de um sistema de wetlands construídos pode ser estimado pela contabilidade de custo dos componentes: escavação, tubulação, pedras, plantas, fechamento e estruturas de controle.

Para este projeto, a estimativa de custos foi elaborada com base nos valores para o estado de São Paulo, setembro/2019, estabelecidos pelo Sistema Nacional de Pesquisa de Custos e Índices da Construção Civil (SINAPI, 2019), cujas composições incluem tanto os materiais, horas de serviços e equipamentos necessários para diferentes atividades relacionadas à construção civil. 


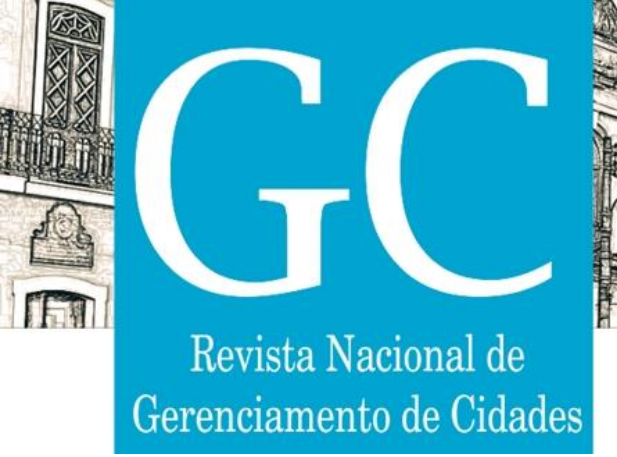

ISSN 2318-8472

Figura 3: Planta baixa e detalhes do sistema de wetlands construídos
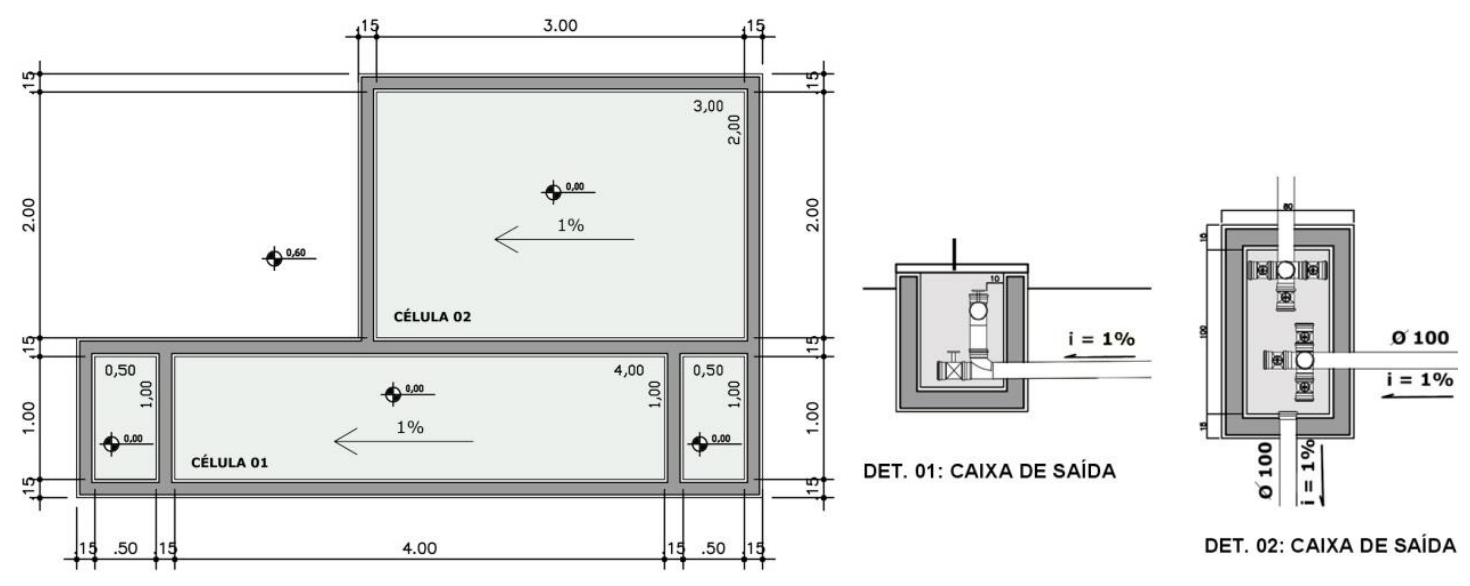

DET. 02: CAIXA DE SAIDA

Fonte: Elaborado pelos autores, 2019.

O sistema escolhido para o projeto são os wetlands construídos de escoamento horizontal subsuperficial. As macrófitas a serem utilizadas podem variar, mas optou-se pelo junco (Juncus spp) na célula 01 e pelo papiro (Cyperus papirus) na célula 02, espécies de eficiência comprovada para estes sistemas (SPERLIG e SEZERINO, 2018). Na Figura 4, são apresentados dois cortes do sistema proposto, com indicação dos locais onde estão previstas as espécies de macrófitas.

Figura 4: Cortes esquemáticos do sistema de wetlands construídos
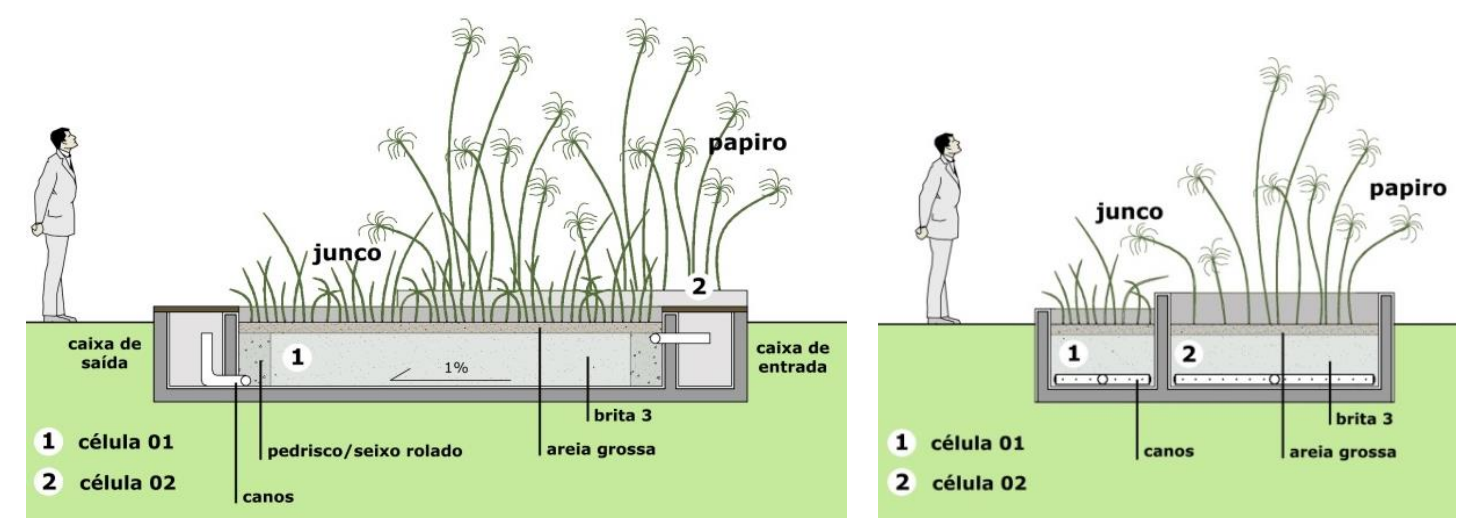

Fonte: Elaborado pelos autores, 2019.

Ainda em busca de soluções que facilitassem a manutenção, mas sem perder de vista o valor estético do conjunto como jardim residencial, as caixas de entrada e saída receberam um revestimento de madeira na tampa. Assim, como a maior parte delas está enterrada, apenas a tampa com revestimento de madeira é visível, assemelhando-se a um banco (quando 


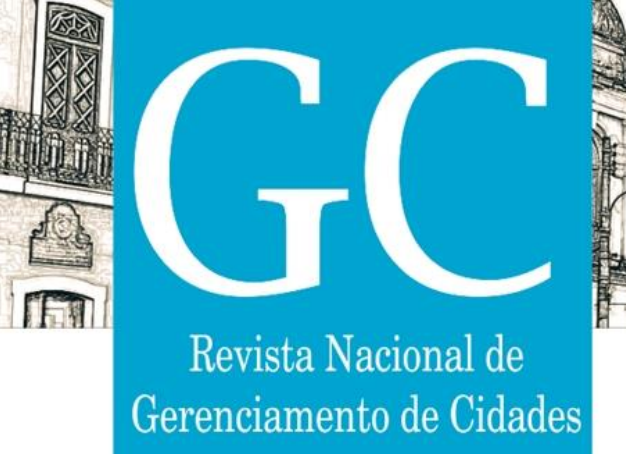

elevadas) ou a um deck (quando no mesmo nível do solo). No momento em que a manutenção se faz necessária, as tampas são fáceis de retirar.

Também se observou que o sistema podia apresentar uma maior redução na carga orgânica, assim como um apelo estético mais interessante, se as duas células de tratamento estivessem associadas a um espelho d'água (que poderia receber algumas macrófitas flutuantes como as ninfeias). Assim, a partir do modelo básico apresentado, com as duas células de tratamento, foram elaborados três modelos alternativos (aumentando a complexidade e o custo do sistema, bem como a área necessária para implantação de cada um deles), conforme Figura 5.

Figura 5: Perspectivas representando os diferentes modelos de wetlands construídos

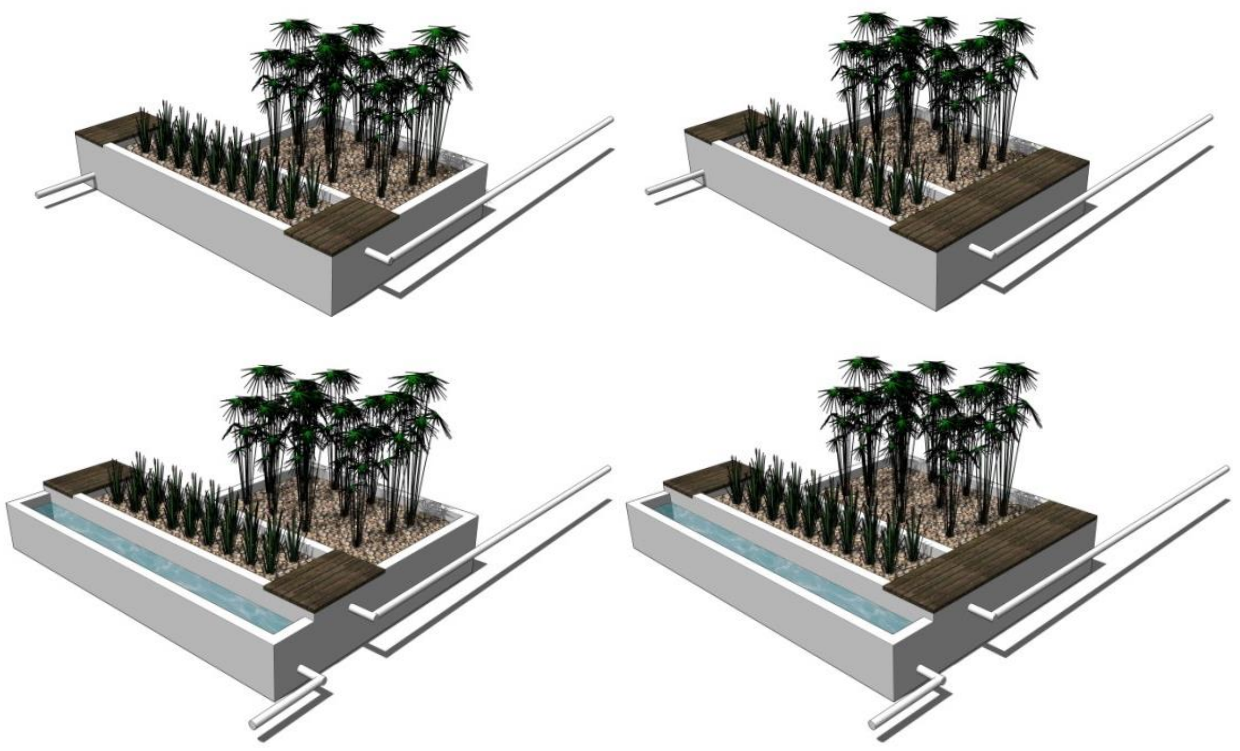

Fonte: Elaborado pelos autores, 2019.

\subsection{Recomendações para implantação}

Aconselha-se implantar o sistema de wetlands construídos no sentido Leste - Oeste, pois desse modo ele irá receber sol durante um período mais longo. Com relação ao local de implantação do sistema, isso irá variar conforme a orientação solar do lote, pois é necessário averiguar qual o local onde irá ocorrer o maior período de insolação.

Assim, quando o lote estiver com a sua frente voltada para o Norte ou Sul é indicado construir o sistema o mais próximo possível do muro face Oeste, pois assim o sistema irá receber o sol da tarde, contribuindo para a vegetação. Já quando o lote estiver com a sua frente voltada para o Oeste ou Leste, é indicado construir o sistema o mais próximo possível do muro face Sul. Foi elaborada uma série de esquemas mostrando o local mais indicado para a implantação do sistema em cada caso, conforme Figura 6, a seguir. 


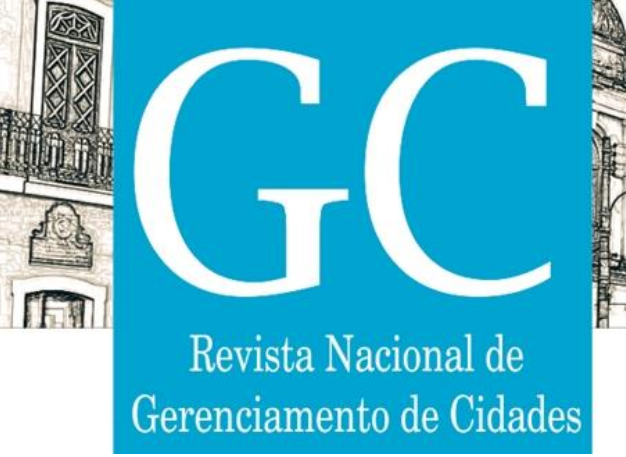

\section{AGRADECIMENTO}

O presente trabalho foi realizado com apoio da Coordenação de Aperfeiçoamento de Pessoal de Nível Superior - Brasil (CAPES) - Código de Financiamento 001. Além disso, os autores também agradecem o apoio da Fundação de Amparo à Pesquisa do Estado de São Paulo (FAPESP) - Código do Processo 07/01812-8.

\section{REFERÊNCIAS BIBLIOGRÁFICAS}

ABNT (Associação Brasileira de Normas Técnicas) NBR 7229: Projeto, construção e operação de sistemas de tanques sépticos. Rio de Janeiro: ABNT, 1993. 15 p.

AVELINO, M.C.G.S. Construção de um sistema de alagados construídos e o comportamento dos parâmetros físicoquímicos e biológicos da fase de maturação dos leitos de fluxo vertical. Bauru, 2012. 109 f. Dissertação (Mestrado em Engenharia Civil e Ambiental) - Universidade Estadual Paulista, Bauru, 2012.

BRIX, H.; SCHIERUP, H.H. The use of aquatic macrophytes in water pollution control. AMBIO Journal of the Human Environment, v. 18, n. 2, p. 100-107, 1989.

CAMPBELL, C.S.; OGDEN, M.H. Constructed wetlands in the sustainable landscape. New York: John Wiley \& Sons Inc., 1999. $270 \mathrm{p}$.

CAVASSAN, O.; CESAR, O.; MARTINS, F.R. Fitossociologia da vegetação arbórea da Reserva Estadual de Bauru, Estado de São Paulo. Revista Brasileira de Botânica, v. 7, n. 2, p. 91-106, 1984.

CHERNICHARO, C.A.L. Tratamento de efluentes de reatores anaeróbios por sistemas de aplicação no solo. In: CHERNICHARO, C.A.L. (Coord.) Pós-tratamento de efluentes de reatores anaeróbios. Belo Horizonte: SEGRAC, 2001.

DAE (Departamento de Água e Esgoto de Bauru), 2019. Estações de Tratamento de Esgoto. Disponível em: <http://www.daebauru.sp.gov.br/2014/esgoto/esgoto.php?secao=tratamento\&pagina=4> Acesso em: 06 out. 2019.

FIGUEIREDO, J.C.; PAZ, R.S. Nova classificação climática e o aspecto climatológico da cidade de Bauru/São Paulo. In: XVI Congresso Brasileiro de Meteorologia, Sociedade Brasileira de Agrometeorologia, 2010, Belém. Anais eletrônicos... Belém: SBMET, 2010. Disponível em: <http://www.sbmet.org.br/cbmet2010/artigos/403_55000.pdf>. Acesso em: 01 out. 2019.

LEONETI, A.B.; PRADO, E.I.; OLIVEIRA, S.V.W.B. Saneamento básico no Brasil: considerações sobre investimentos e sustentabilidade para o século XXI. Revista de Administração Pública, v. 45, n. 2, p. 331-348, 2011.

SINAPI (Sistema Nacional de Pesquisa de Custos e Índices da Construção Civil), 2019. Gerência Nacional Padronização e Normas Técnicas. Caixa Econômica Federal. Relatórios de Insumos e Composições para o Estado de São Paulo. Disponível em: <http://www.caixa.gov.br/site/Paginas/downloads.aspx.> Acesso em: 07 out. 2019.

U.S.EPA (United States Environmental Protection Agency) Manual constructed wetlands treatment of municipal wastewaters. EPA/625/R-99/010, September/2000, Cincinnati: U.S. EPA, 2000. 158 p.

VAN KAICK, T. S. Estação de tratamento de esgoto por meio de zona de raízes: Uma proposta de tecnologia apropriada para saneamento básico no litoral do Paraná. Curitiba, 2002. 128 f. Dissertação (Mestrado em Tecnologia) - Universidade Tecnológica Federal do Paraná, Curitiba, 2002. 


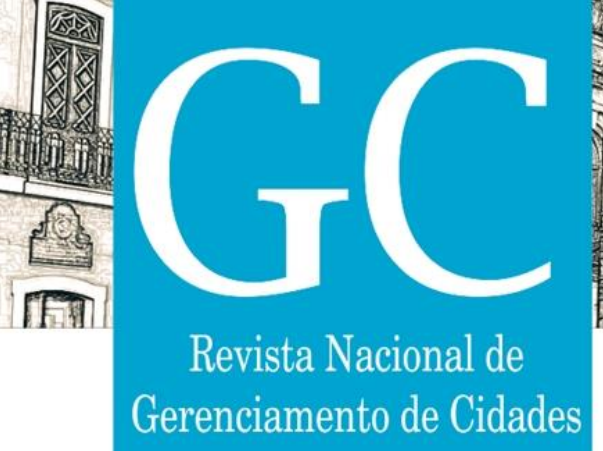

VON DREIFUS, T. Tratamento de águas residuárias por alagados construídos de fluxo subsuperficial horizontal, utilizando vetiver (Chrysopogon zizanoides L.): Avaliação e desempenho de três leitos distintos. Bauru, 2012. $84 \mathrm{f}$. Dissertação (Mestrado em Engenharia Civil e Ambiental) - Universidade Estadual Paulista, Bauru, 2012.

VON SPERLING, M.; SEZERINO, P.H. 2018. Dimensionamento de wetlands construídos no Brasil. Documento de consenso entre pesquisadores e praticantes. Boletim Wetlands Brasil, Edição Especial, dezembro/2018. 65 p. Disponível em: <http://gesad.ufsc.br/boletins/>. Acesso em: 01 jul. 2019.

ZANELLA, L. Plantas ornamentais no pós-tratamento de efluentes sanitários: Wetlands-construídos utilizando brita e bambu como suporte. Campinas, 2008. 189 f. Tese (Doutorado em Engenharia Civil) - Universidade Estadual de Campinas, Campinas, 2008. 